\title{
La sección Cultura hoy: De las descripciones teóricas a la realidad práctica. Estudio de caso de medios impresos en España
}

\section{Culture section today. From theoretical descriptions to practical reality. Case study of print media in Spain}

\author{
Montserrat Jurado Martín*
}

*Universidad Miguel Hernández de Elche, Spain

\section{Resumen}

Este artículo estudia la sección Cultura de los medios impresos con el objetivo de concretar la coherencia entre las propuestas teóricas de los investigadores y el ejercicio práctico de la profesión tomando como referencia el caso de España. Se desarrolla una amplia revisión bibliográfica de propuestas teóricas y empíricas, poniendo en relación los trabajos que sugieren cómo debería ser esta especialización y los resultados de investigación de quiénes describen cómo es en la práctica. ¿Hay una brecha entre ambos? Y si fuera así, ¿dónde estriban las diferencias? La presión digital favorece los desequilibrios entre las aportaciones científicas y académicas y las rutinas de trabajo. Este planteamiento sirve de base para el estudio de caso en las versiones impresas de El País, $A B C$ y $E I$ Mundo, donde se ha aplicado el método del análisis de contenido comparativo. Se observa el peso que ocupa la sección en relación al resto del diario, temáticas, géneros periodísticos y elementos complementarios empleados. El trabajo concluye que hay aspectos teóricos que se cumplen y otros que se quedan en utopías, así como la evidencia de que esta especialización se encuentra en un proceso de transformación e innovación en parte influenciada por su entorno digital.

Palabras clave: Sección Cultura; periodismo cultural; industria cultural, teoría y práctica; géneros periodísticos

\section{Abstract}

This paper studies the Culture section of the printed media with the aim of specifying the coherence between the theoretical proposals of the researchers and the practical exercise of the profession, as reference the case of Spain. A bibliographic review of theoretical and empirical proposals is developed, to relate the works that suggest how this specialization should be and the research results who describe what it is like in practice. Is there a gap between the two? And if so, where are the differences? Digital pressure favors imbalances between scientific and academic contributions and work routines. This approach serves as the basis for the case study in the printed versions of El País, $A B C$ and El Mundo, where the comparative content analysis method has been applied. We observe the weight of the section in relation to the rest of the newspaper, issues, journalistic genres and complementary elements used. The paper concludes that there are coincident theoretical aspects and others that remain in utopias, as well as the evidence that this specialization is in process of transformation and innovation, partly influenced by its digital environment.

Keywords: Culture section; cultural journalism; cultural industry, theory and practice; journalistic genres

Submitted: 2th August 2018

Accepted: $10^{\text {th }}$ March 2019

\section{How to quote this article:}

Jurado Martín, M. (2019). La sección Cultura hoy: De las descripciones teóricas a la realidad práctica. Estudio de caso de medios impresos en España. Observatorio, 13(2), 142-166. 


\section{Introducción ${ }^{1}$}

Muñoz-Torres (2002, p. 179-184) destaca la importancia del estudio de lo práctico frente a lo teórico rescatando esta frase de Aristóteles: "La vida es acción (praxis) y no reproducción (poíesis)". Decía que sólo entendiendo el conocimiento práctico se podrá entender el significado de los textos noticiosos. Explica que cuando el entendimiento teórico reflexiona, su meta no es la acción sino el conocimiento, versar sobre lo universal y lo necesario, mientras que la acción es particular y contingente. Núñez Ladeveze (2004, p. 32-33) destaca la importancia de encontrar el término medio entre teoría y práctica: la teoría aporta la abstracción y la generalización pero no sustituye al metalenguaje que describe.

En un momento de transformación de la sección Cultura en los medios de comunicación como consecuencia de la competencia que suponen los medios digitales y la adaptación de contenidos y géneros a los gustos de la audiencia (Jurado y Peña, 2018, p. 13), el objetivo de este trabajo es estudiar y comprobar la coherencia entre las propuestas de los investigadores sobre qué debería ser la sección Cultura y, en consecuencia, la especialización del periodismo cultural y cómo es en la práctica. ¿Hay desfase entre ambos? Éste es el punto de partida y la hipótesis de trabajo. Y si fuera así; ¿dónde estriban las diferencias?, y ¿varían según el medio?

Por esta razón se desarrolla una revisión bibliográfica amplía tanto de propuestas teóricas como empíricas en el caso del periodismo cultural. Éstas sirven de base para el estudio de caso que tiene por objeto comprobar la coherencia entre la teoría y la práctica profesional, analizando los contenidos en el que se desarrolla la sección Cultura, contemplando las características de los textos publicados, temáticas, géneros periodísticos y elementos complementarios clásicos o innovadores de la sección. Se han tomado como referencia los medios impresos de tres medios emblemáticos en España, El País, El Mundo y $A B C$.

El medio impreso constituye el eje hegemónico para los investigadores, que evidencia su valor como documento histórico y mapa para la interpretación de temas, agentes y consenso cultural de cada periodo histórico (Golín et al., 2014, p. 1). Dado que "los medios tradicionales no desaparecerán, pero sí las empresas que no se adapten a este mercado" (Orihuela, 2012, p. 46) y que el papel no ha muerto y no parece que la era digital haya cavado la tumba del periodismo en soporte papel (López, 2004, p. 15), estimamos de interés que los medios impresos sean el punto de partida del estudio. Este interés se justifica en la importancia que la sección Cultura ha tenido tradicionalmente en los medios impresos y que los digitales han heredado. La pugna o tensión entre medios impresos y digitales lo fue en el ámbito empresarial y afectó dramáticamente a la organización empresarial, lo que desembocó en la crisis y posterior renovación de contenidos y fundamentalmente en la forma en la se elaboran éstos. Lo cierto es que las versiones digitales en el ámbito de la cultural siguen respetando rutinas de trabajo en lo relativo a contenidos, temáticas y elección de los géneros periodísticos, por lo que sigue siendo de actualidad observar la sección cultural en sus versiones impresas.

\footnotetext{
${ }^{1}$ Atendiendo a la igualdad de género se ha recurrido a la terminología neutra de la lengua española para la descripción de sustantivos o determinantes que acompañan a sustantivos que impliquen al mismo tiempo a hombres y mujeres. De este modo palabras como profesor, el docente o los investigadores, hacen referencia a profesor/a, la/el docente 0 los/las investigadora/os.
} 


\section{Delimitación del objeto de estudio}

\section{La sección Cultura en su contexto}

La sección Cultura es una forma de organización de la información que ofrece un producto informativo con una estructura ordenada. El origen de la organización en secciones y la tematización obliga a mencionar su contexto. El primer ámbito de estudio inmediatamente superior es el Periodismo Cultural recogido dentro de la especialización periodística (Villa, 2000) (Gómez-Escalonilla, 2014), a su entendido como una consecuencia del proceso de tematización de la empresa periodística. Para su estudio se lleva a cabo una aproximación bibliográfica que toma como referencia a los autores más representativos desarrollando una revisión que parte del todo a lo específico. El todo se inicia en la necesidad de tematización de los medios y la creación de secciones; seguido de la especialización periodística; y un tercer paso es el periodismo cultural. No pretende ser una revisión total de la bibliografía existente, sino un acercamiento que ayude a conocer la relación entre las aportaciones de los autores. Este proceso queda recogido en la figura 1.

Figura 1: Organización de estudio del estado de la cuestión

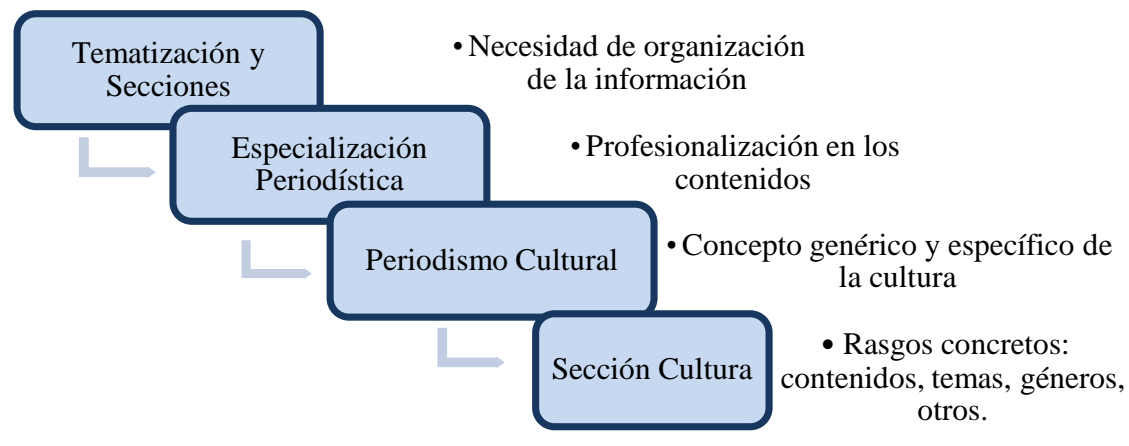

Fuente: Elaboración propia

Casi de obligado cumplimiento es concretar qué se entiende por 'cultura'. Un concepto que varía en función de la interpretación que le dé la sociedad en un momento histórico y a la vez determinado por la clase dominante (Bourdieu, 1993, p. 23 y 79). La Unesco² concreta el fenómeno 'cultura' en la Normativa Internacional para los campos de Ciencias Tecnología en los ámbitos de Antropología cultural, Geografía cultural, Política cultural, Cultura y personalidad -en el ámbito de la evaluación y diagnóstico en Psicología-, y Cultura y personalidad -en el ámbito de la Psicología Social y Sociología Cultural-.

Varios autores hablan del concepto con definiciones que se remontan al vocablo del latín "cultivo de la tierra" (Díez et al., 2005, p. 29) y etimológicamente del verbo latín collere (Esteve y Fernández del Moral, 1999, p. 133). El término cultura es polisémico (Zallo, 2011, p. 23), extenso y heterogéneo (Izquierdo, 2014, p. 1.122), abstracto en función del país y las épocas (Ruano, 2009: 21) y encuentra sus primeros estudios en la influencia del marxismo y el psicoanálisis de la Escuela de Frankfurt (Ruano, 2009, p. 36). Raymond Williams (2017: 209-210) lleva a cabo una revisión que deja de nuevo en evidencia esta dificultad del término: "La idea de 'cultura' es, en cualquier contexto, notoriamente difícil de usar".

2 Normativa Internacional para los campos de Ciencias Tecnología de la Unesco accesible en: http://www.ciencia.gob.es/portal/site/MICINN/menuitem.8ce192e94ba842bea3bc811001432ea0/?vgnextoid=363ac948 7fb02210VgnVCM1000001d04140aRCRD\&vgnextchannel=28fb282978ea0210VgnVCM1000001034e20aRCRD 
Hanitzsch (2006) llegó a la misma conclusión una década antes como resultado de las 300 entrevistas a periodistas preguntados sobre el concepto 'cultura'.

\section{Binomio: cultura y periodismo}

Rodríguez Pastoriza explicaba en relación a la cultura desde el enfoque del periodismo que:

"Existe una tradicional noción de cultura, en su sentido genérico, que concibe el término como un conjunto ordenado y construido de conocimientos, creencias, códigos morales, leyes, costumbre y otras habilidades adquiridas por el hombre, que le permiten desarrollar el sentido crítico, el gusto y el juicio, y situarse en el espacio, en el tiempo y en la sociedad" (2003, p. 15).

Iván Tubau (1982, p. 10) decía que es una forma de conocer y difundir los productos culturales de una sociedad a través de los medios. José Luis Rodríguez González (2011) recordaba la visión elitista, con influencias en las Bellas Artes, la Antropología, la Sociología y finalmente el Periodismo. Y finalmente Gómez-Escalonilla (2014: 89) afirmaba que "periodismo y cultura confluyen de manera natural, y es que en la sociedades modernas los medios también son cultura". En definitiva, la definición exacta es difícil de concretar ya que el periodismo cultural "no es uniforme ni en el contenido ni en su aspecto formal ni en la naturaleza de sus públicos" (Villa, 2000).

Las aportaciones de Valle (2014: 129-131) vislumbran un nuevo enfoque que, estudiado en el caso peruano, puede ser aplicado al resto del mundo. Valle describe que el periodismo cultural en medios impresos ha evolucionado desde las teorías clásicas a convertirse en contenido multicultural como consecuencia de una sociedad también multicultural. En este proceso ha sido crucial la inclusión de contenidos propios del periodismo de espectáculos en los propios de la sección Cultura y la concepción del concepto cultura como 'cultivo', es decir, "replantear no significa desechar lo anterior (...) de manera que la sección está abierta a identificar nuevos iconos de cultura" (...) y, en definitiva, a explotar y transmitir la dimensión simbólica de las producciones culturales de una sociedad".

\section{Tematización y organización en secciones}

Debemos reflexionar sobre la diferenciación entre tematización y organización en secciones. Parece que estemos hablando del mismo fenómeno pero no es así. Sería como hablar del océano y de la vida marina, o del software y el hardware. Ambos forman simbiosis y son necesarias la una para la otra. La tematización responde a una necesidad del medio de recoger lo novedoso de la realidad social (Fontcuberta, 1998, p. 49), mientras que la organización en secciones en una consecuencia de la tematización de los contenidos. Así, un mismo tema pueda variar de sección en la que se publica en función del enfoque [temático] del medio (Rodríguez, 2006, p. 15).

Cuando se habla de tematización hablamos del contenido de la superficie redaccional, "de la valoración que cada medio efectúa de todos los aconteceres de la realidad y la intención de trasmitirlo al público. (...) Los medios ofrecen en sus diversas secciones, como si fuera un gran almacén, los productos de gran 
consumo" (Fontcuberta, 1998, p. 41-43). El estudio de la tematización abarca los relativos a la teoría de la construcción del temario (López, 2007, p. 109) y la agenda-setting (Rodrigo, 1996, p. 63).

Los autores describen que los temas se han ido acomodando de forma más o menos organizada (Edo, 1999, p. 78). El criterio del medio para organizar la información en secciones es facilitar al lector el acceso a la información, por lo tanto, es un criterio de ordenación y los principales son: la tematización y la actualidad (Núñez, 1995, p. 42). Martínez Fresneda (2011, p. 107-108) describe el proceso de tematización como una serie de desequilibrios derivados de los abusos de las industrias periodísticas: concentración y diversificación de medios, vinculación con el poder, globalización, influencia de las tecnologías o la rentabilidad.

La ubicación de la información en una u otra sección determina también la intencionalidad del medio y "no es tan inocente ni ritual" (Núñez, 2004, p. 43). De este modo se pueden magnificar o ensombrecer textos que en función de la sección se ven más o menos beneficiados. Esta intencionalidad no responde siempre a criterios relacionados con la noticiabilidad, sino a otros más productivos, por pertenencia a un colectivo o a una organización empresarial (Armentia y Caminos, 2009, p. 208-209), "una distorsión que se aleja de los mecanismos voluntarios de manipulación".

Núñez Ladevéze (1995, p. 43) explica que las comunes a todos los medios impresos y audiovisuales son: política internacional, política nacional, local, economía, cultura, sucesos y deportes. La forma en las que se organizan para presentarlas a los lectores determina el perfil del lector al que se dirige el medio. Una distribución seccional clásica pretende identificarse con un segmento conservador y de edad avanzada o media (López, 2004, p. 83).

\section{La especialización periodística}

La especialización periodística es la disciplina que ordena los contenidos informativos proporcionando una síntesis globalizadora, requiere una especialización concreta (Esteve et al., 1999, p. 9 y 129) y se define como "aquella estructura informativa realizada por un experto en la que, de forma clara y fiable, analiza la realidad coyuntural de una determinada área de actualidad, profundizando en sus motivaciones y aportando posibles soluciones" (Esteve, 2012, p. 9-10). Cumple una función didáctica porque completa los datos de las informaciones generalistas. Puede tener cierto grado de persuasión y debe ser divulgativa y no "simplificar la complejidad de las manifestaciones culturales" (Rodríguez, 2012, p. 162). Esta afirmación da respuesta a la triple especialización del periodismo moderno (Quesada, 1998, p. 18): la especialización por contenidos, por audiencias y por medios de comunicación. Según Concha Edo (1999, p. 78-79), "las distintas especialidades del periodismo responden a la urgencia que tienen los lectores, los radioyentes y los telespectadores de asimilar los cambios culturales, científicos, económicos, sociales y políticos", y añade que definirán mejor una sección cuánto más coherentes sean los contenidos y el lenguaje empleado.

Tanto es así que la especialización está completamente sistematizada en las rutinas periodísticas ligada sin más crítica o valoración a los contenidos y no al tipo de medio y al perfil de su público (Fontcuberta, 1998, p. 49-50). Además es una consecuencia del incremento de contenidos y la forma de afrontar el cambio y las consecuencias que para la profesión tiene Internet, que con más incidencia afecta a los espacios culturales, donde "cualquiera con banda ancha puede jugar a ser Carlos Boyero vía blog o cambiar las previsiones de taquilla de alguna superproducción de Hollywood" (García, López y Ruiz, 2011, p. 16). 


\section{Periodismo especializado en cultura: Periodismo cultural}

Según Rivera (2003), "todo periodismo en definitiva es un fenómeno 'cultural' por sus orígenes, objetivos y procedimientos" y para Martínez Fresneda (1999, p. 102) "la comunicación forma parte de la estructura misma de la sociedad y por eso la información es consecuencia del sistema comunicativo". De ahí que para muchos autores estas generalizaciones son insuficientes (Herrero, 1999, p. 137) ya que casi supone afirmar que toda comunicación es periodismo. El mismo Rivera concretaba que el periodismo cultural es:

\footnotetext{
"Una zona muy completa y heterogénea de medios, géneros y productos que abordan con propósitos creativos, críticos, reproductivos o divulgativos los terrenos de las 'bellas artes', las 'bellas letras', las corrientes del pensamiento, las ciencias sociales y humanas, la llamada cultural popular y muchos otros aspectos que tienen que ver con la producción, circulación y consumo de bienes simbólicos" (Rivera, 2003, p. 19)
}

Se trata de una "especialización periodística compleja que informa sobre los temas de artes y letras, de la cultura popular y de los campos temáticos, con el fin de educar y promocionar las diversas manifestaciones artísticos-culturales del ser humano" (Zambrano et al., 2010, p. 78) y "ayuda a incrementar el nivel cultural y de conocimiento de la población" (Gómez-Escalonilla, p. 2014: 88-89). No cabe duda que el periodismo cultural es la práctica informativa que se ocupa de la difusión de la cultura, "trata de canalizar la información que se genera en torno al mundo de la cultura" (Rodríguez, 2006, p. 13) y construye y deconstruye el imaginario simbólico de la sociedad (Delponti y Pestano, 2012).

Pero en ocasiones sufre presiones externas de las industrias culturales y del propio medio por satisfacerlas con más facilidad que otras secciones. Llegados a este punto se pierde calidad y se cae en una rutina propia del periodismo generalista (Rodríguez 2006: 10), en contenidos que no responden a la realidad del fenómeno cultural de su contexto, sino que obedece a los compromisos de mercado e intereses de los dueños del medio (Bello y otros, 1994: 150), más interesados en la producción regida por criterios competitivos de producción periodística y alejándose del interés público (Kristensen, 2010, p. 69). Tal y como afirman Cruz y Rosero (2012: 183) "se cae en el unifuentismo, el silenciamiento de temas y la ausencia de agenda, y en una autocensura desde los propios medios".

\section{La sección Cultura hoy: teoría y práctica}

Recogemos propuestas de investigadores en torno a la sección Cultural y establecemos dos tendencias: propuestas que centran aspectos de los orígenes y son valoraciones descriptivo-teóricas, y propuestas eminentemente críticas resultados de estudios empíricos.

Del primer grupo destacan las afirmaciones que dicen de la sección Cultura que es una de las más clásicas del periodismo, encontrando sus orígenes en los folletones culturales de los periódicos franceses. Se define como el espacio dedicado por los medios para el tratamiento de las manifestaciones artísticas, literarias y científicas (Esteve et al., 1999, p. 32 y 133). Para numerosos autores se trata de una de las secciones más rica en variedad de temas y géneros (García López y Ruiz, 2011, p. 248; Sánchez Calero, 2008, p. 173). 
En general coinciden en determinar que esta sección debe tener espíritu crítico, comentarios interpretativos, seriedad, diseño atractivo (Zambrano et al., 2010, p. 72); debe reflejar lealmente las problemáticas globales de una época, satisfacer las demandas sociales e interpretar la creatividad potencial del ser humano (Rivera, 2003); hacernos comprender lo ocurrido (Rodríguez, 2006, p. 14), contextualizar los fenómenos culturales más allá de las gramáticas del cine o la literatura relacionándolos con lo que los engloba (Arráez, et al., 2014, p. 58) y emplear un lenguaje específico y cuidado, aunque no excesivamente técnico (Sánchez Calero, 2008, p. 173).

No es una de las secciones estrella como pueda serlo Nacional o Internacional, pero tiene una importancia notable dentro del periodismo especializado (Barei, 2000) y del periodismo en general, ya que, según Llano (2008, p. 431) "a pesar de tener una posición 'no adelantada', ser una sección 'editorialmente blanca' y cuyos temas con escasa frecuencia llegan a la portada, se trata de una área delicada desde el punto de vista político, por el gran prestigio que tiene". El autor señala la importancia de esta sección desde el punto de vista del prestigio de las facciones ideológicas que apoya cada medio.

En el segundo grupo, caracterizado por aportaciones críticas basadas en resultados de trabajos fundamentalmente empíricos, los autores dicen de la sección que se cae más en la opinión que en la interpretación (Camacho, 2010, p. 162), la noticia pierde interés frente a lo literario y dosis de subjetividad (Cortés y García, 2012, p. 48); "en los medios escritos se tiende a ejercer la crítica más que a informar de los contenidos" (Rodríguez, 2006, p. 18); frente a afirmaciones que manifiestan que la prensa cultural emplea las rutinas del periodismo generalista y no las que le son propias (Rodríguez, 2012, p. 163). Jurado (2011, p. 178) afirma que se trata de una sección en la que se repiten escenarios, géneros periodísticos, "hay informaciones que rara vez aparecen" y donde los temas sobre cine, música y literatura copan prácticamente todas las páginas.

Se añaden los estudios que valoran el contenido cultural en el ámbito de la industria cultural. Félix Rebollo (2000, p. 136) habla de los temas literarios de los periódicos: "la calidad literaria no se puede confundir con los éxitos de venta (...) Son los factores extraliterarios los que difuminan la verdadera crítica". Estos se subordinan a las presiones del entorno industria-cultura (Rodríguez, 2006, p. 14; Ruano, 2009, p. 53) y los intereses empresariales del medio, descritos por Martínez Fresneda (2011, p. 107) como el primer desequilibrio en la selección de la información. En un contexto en el que el contenido cultural se asume como algo secundario algunos auguran el fin de la sección cultural cuando no supone ingresos por publicidad para el medio (Aguilar, 2009). "La información cultural existe, pero es un bien escaso en los medios de comunicación colectiva del tercer milenio" (López, 2004, p. 377).

\section{Jerarquía de textos}

La producción periodística se inicia con la inclusión y exclusión de hechos noticiables (López, 2007, p. 45) seguido de la jerarquización. "Jerarquizar significa ordenar, priorizar, destacar algo sobre la masa y relativizar otros temas", explica el autor. A esa valoración hay que sumar la titulación, la iconografía y la disposición morfológica de las informaciones para determinar la importancia del texto en relación al todo (López, 2004, p. 81).

La jerarquización puede ser entendida de dos maneras: la relativa al orden en el que se ofrecen las secciones y, dentro de una misma sección, la relativa al orden y características en el que se ofrecen las informaciones. "Los medios jerarquizan la información para valorar las noticias a las que dan más 
importancia y lo hacen con dos elementos: las fuentes y los recursos formales y estéticos (Fontcuberta, 1998, p. 55).

El orden marca la importancia de los temas, pero a este criterio hay que añadir otros como su extensión y los elementos que acompañan al texto. Manuel López (2004, p. 82) explica que para conocer la intención del medio escrito para incidir en las clases sociales a los que se dirige basta con analizar el porcentaje de páginas dedicadas a cada sección, orden de presentación de estas secciones, jerarquización gráfica de temas, superficie dedicada a cada texto, el valor de la iconografía, de la titulación y la complementariedad con otros medios: "La forma, pues, condiciona el contenido".

\section{Temas}

Concha Edo (1999: 78) explicaba que los temas se engloban dentro de una sección por su coherencia temática. Esta afirmación invita a la reflexión sobre la organización de estos. De ahí que el bloque se ha constituido en dos apartados en relación a las propuestas de los investigadores: por una parte, los temas que debería recoger la sección Cultura, resultando más teórico-descriptivos y, por otra, los que realmente integran dicha sección, resultados generalmente de estudios empíricos.

Del primer grupo, las temáticas que los autores (Esteve et al., 1999, p. 137) (Rodríguez, 2006, p. 5) estiman que podrían enmarcarse en esta sección son teatro, literatura, cine, música y arte, a lo que se puede añadir danza y arte, y nuevas tecnologías (Rodríguez, 2010, p. 162). Jorge Luis Rodríguez (2011) describe los temas de la sección Cultura:

"Es así como un terreno que desde sus inicios estuvo consagrado a la filosofía, la literatura, el teatro, la escultura, la pintura y la arquitectura, ahora asume dentro de él a otras tan antiguas también como la danza, la artesanía y a las más emergentes y novedosas dentro de la evolución histórica de las sociedades como el cine" (Rodríguez, p. 2011).

Francisco Rodríguez (2006, p. 11) hablaba de informaciones de la "alta cultura", recogidas en la sección Cultura, mientras que el resto se relaciona con el ámbito del arte popular y suele derivarse a otras secciones, "fundamentalmente al área de Sociedad". En esta intersección entre Sociedad y Cultura, Rafael Llanos (2008, p. 430) concreta que: "A diferencia de lo que ocurre con la poliédrica sección de Sociedad, la de Cultura nos ofrece un tipo mucho más homogéneo de contenidos: noticias relativas a la actualidad e las bellas artes, de la producción musical y escénica, de la literatura, el cine, etc."

El segundo grupo, fundamentado en resultados de estudios empíricos, pocas veces establece un ranking de los que son tratados en el ámbito de la especialización periodística en la sección Cultura, pero los autores coinciden prácticamente en los mismos:

-Luisa Sánchez Calero (2008, p. 174): exposiciones, presentaciones teatrales, libros.

-Jurado (2011, p. 186-190): cine, arte, literatura y música.

-Ruth Rodríguez (2010, p. 162): literatura, arte plástico (pintura, escultura, arquitectura); música, teatro, danza, cine, arte y tecnología.

-Dillon (2011): literatura, artes visuales, música, cine, teatro, disciplinas no artísticas y otros. 
-Violeta Izquierdo (2014, p. 1.123) propone: pintura y escultura, cine, teatro y música. Y otros "menores" como: arte, arquitectura, moda o gastronomía.

De una manera u otra, ambas tendencias coinciden en lo genérico y apuntan al entrelazamiento entre contenidos de cultural, sociedad y espectáculos. Kristensen (2012, p. 26) sostiene que los límites entre el periodismo cultural y de espectáculos se ha difuminando y casi puede considerarse que son "inseparables". Su estudio está centrado en el caso danés y basado en el análisis amplio de medios impresos durante el siglo XX y XXI y entrevistas en profundidad. Concluye que las trasformaciones sociales y mediáticas de la sociedad son las responsables de este cambio de contenidos en los medios impresos. En general, los textos no profundizan en los temas (García, et al., 2011, p. 250). Son esponja de la tendencia sobre la influencia de los intereses empresariales obviando su labor social y responsabilidad cultural y difundiendo como información contenidos comprometidos comercialmente. $Y$ aunque en su origen se le diera más peso al valor crítico (Rodríguez, 2006, p. 48-64), hoy en día son el 'final feliz' después de todas las noticias amargas (Rodríguez, 2006, p. 77).

\section{Géneros periodísticos}

Hablar del origen de los géneros periodísticos obliga a hablar de las propuestas clásicas de Martínez Albertos (2004a, 2004b, 1989), Núñez Ladevéze (2007), Casals (2005), Armañanzas y Díaz Noci (1996), Rodríguez Pastoriza (2006), Santamaría (1994) o Gomis (1991), por poner algunos ejemplos destacables. Todos comparten la idea de que los géneros son un principio de orientación para el lector (Martínez Albertos, 2004, p. 267) (López, 2012, p. 11), ayudan a organizar el trabajo en las redacciones e "indican el propósito general de los mensajes" (Moreno, 1998).

Los autores no se ponen de acuerdo en denominarlos de la misma manera. Hay falta de coincidencia en las palabras que las designan, pero "hay una sola condición: que el periódico se moleste en diferenciar tipográficamente un género de otro. Esta diferencia constituye una garantía para el público" (Grijelmo, 2006, p. 28) (Armentia et al., 2009, p. 80) ya que cada género tiene su ámbito de aplicación (López, 2004, p. 88) y el periodista especializado en cultura no puede olvidar su papel de mediador (Barei, 1999). Los géneros de cada grupo inspirados en las propuestas de Martínez Albertos y que concretan la intencionalidad del emisor (Armentia et al., 2009, p. 84-86) de forma sintetizada son: géneros informativos: información, reportaje objetivo, entrevista de citas; géneros interpretativos: reportaje interpretativo y la crónica; géneros de opinión: editorial, columna, crítica y artículo de opinión (Mejía, 2012, p. 209). El mismo autor completa la propuesta añadiendo la entrevista perfil a los géneros interpretativos, el ensayo a los de opinión, y un cuarto grupo que denomina elementos complementarios, que lo integran: despieces, bloques de antecedentes, infografías y caricaturas, chistes y gráficos.

Son muchos los autores que con el uso de Internet hablan de hibridación de los géneros (Sabés y Carniel, 2013, p. 20) o nuevos textos mixtos (Fernández Parrat, 2001) y de la adaptación de estos a los nuevos formatos web (Domínguez y Doval, 2013, p. 195). A puertas del siglo XXI, Cantavella (1999, p. 72-73) valoraba el futuro de los géneros periodísticos prediciendo que:

- Habrá un mayor uso de los géneros interpretativos en detrimento de los informativos;

- "La noticia quedará quintaesenciada en los breves" o "reportajeada"; 
- Aumento del valor documental en forma de despieces informativos dentro de textos interpretativos;

- $\quad$ Apuesta por la columna menos subjetiva;

- Apuesta por un reportaje "dotado de solidez, cargado de datos ciertos y de opiniones solventes, que informa, explica y, consecuentemente con ello, orienta a la opinión";

- Incremento de la entrevista tipo semblanza, que requiere más tiempo;

- Aparición de un nuevo tipo de género: el diálogo, donde uno o más individuos conversan entre ellos sobre un tema conflictivo;

- Pérdida de nitidez de la opinión y la información.

En relación a los géneros periodísticos empleados en la sección Cultura, y tomando como referencia los resultados de estudios empíricos, los más frecuentes, y por mencionar algunos ejemplos, son:

- Cavallín (2009: 96): la noticia, la entrevista, el reportaje y la crónica;

- Esteve et al. (1999: 134): la noticia, la reseña y la crónica, con carácter informativo y la crítica;

- $\quad$ Ruth Rodríguez (2012: 173-177) menciona la crítica, el reportaje y la entrevista contextual.

- Luisa Sánchez Calero (2008: 174) concreta que los géneros más repetidos son, y por este orden: el breve y la crítica; y

- Jurado (2011: 192-194) concluye en su análisis y en este orden: el reportaje interpretativo, la noticia y el breve.

Manuel López (2004, p. 88-89) afirmaba que el futuro de la sección pasa por "literaturizar recursos estilísticos y estructuras como una nueva oferta para el lector". Este fenómeno no consiste en una "trascendencia imaginativa", sino en "maridar nuevamente periodismo y literatura (...) y narrar nuevas historias con una argumentación lógica y más atractiva para el lector". En esta línea Cruz y Rosero (2012, p. 183) también reclaman que los medios, dado el exceso de géneros informativos en el ámbito cultural, rescaten los interpretativos y de opinión, de cara a generar debate y análisis de los fenómenos culturales.

\section{Elementos complementarios}

El estudio de la sección Cultura se detiene en este punto en los elementos que implican una innovación (Santos: 2015, p. 307) y una jerarquización de los contenidos, "ya que jerarquizar supone revestir la información con infografías, fotografías y detalles complementarios" (López, 2007, p. 48). Estos recursos tienen como objetivo no solo informar, sino ayudar al lector a comprender la información. Son nuevos formatos que facilitan la lectura, desmenuzan el contenido y se pueden sintetizar, en el caso de los medios impresos en: despiece, noticia complementaria y fotonoticia (López, 2002, p. 71-87). Armentia y sus colegas (2009, p. 81) consideraban que en la prensa diaria se está produciendo la pujanza de nuevos géneros visuales (fotografía) y los que combinan lo visual y lo textual (infoperiodismo). La infografía se ha utilizado para relacionar datos, contextualizar o con un fin formativo (Ivars, 2016, p. 149), logrando una buena información recurriendo al lenguaje visual en lugar de un discurso verbal (Colle, 1998 , p. 1; 2004, p. 1); e incluso para completar la información cuando no se dispone de fotografías y 
facilitar la comprensión de un asunto (De Pablos, 1993, p. 273). Con Internet, los recursos habituales abren sus posibilidades de hipertextualidad, multimedialidad, interactividad y simultaneidad. Salaverría (2008, p. 19) daba al medio impreso un nivel bajo en las tres primeras y ninguno en el de simultaneidad. En este ámbito, la hipertextualidad se daba en los textos y en los despieces; la multimedialidad en los textos y las imágenes; y la interactividad en las cartas de los lectores. Además de los mencionados, Santos (2015, p. 307) añade a los anteriores que el medio impreso bebe del entorno digital e innova modificando el modelo editorial, la identidad de marca, extensiones y posicionamiento, compromiso con el público, etc. Aunque los espacios de comunicación se han trasformado, y con ellos los medios de comunicación y los lugares y soportes de difusión, la necesidad de comunicación sigue siendo la misma. De este modo las redes sociales abren nuevas posibilidades que también afectan al periodismo cultural aumentando la variedad (Cavallín, 2009, p. 91-93).

\section{Metodología}

Para conocer la relación entre las aportaciones teóricas y las prácticas desarrolladas por los investigadores y comprobar si existe desequilibrio entre ambas en la sección Cultura, se ha recurrido al método del análisis de contenido. La revisión bibliográfica para observar el estado de la cuestión puede resultar inabarcable y presuntuosa, por lo que es objetivo de este trabajo recoger de forma acotada y honesta los trabajos clásicos más emblemáticos así como los actuales que se centran de forma específica al tema propuesto de cara a ofrecer un contexto lo más completo posible de la problemática que se está tratando. Los autores que han servido de referencia para el marco teórico, que a su vez sustenta las plantillas o rúbricas de análisis de contenido, lo han sido fundamentalmente por sus estudios empíricos, o por ser los más representativos en esta especialización cultural. Las versiones digitales en el ámbito de la cultural siguen respetando las rutinas de trabajo en lo relativo a contenidos, temáticas y uso, por los que la versión impresa sigue siendo el referente en el proceso de observación de los contenidos en esta sección. Por este motivo, son de especial relevancia los estudios sobre periodismo cultural de Cruz y Rosero en Ecuador (2012), Baptista (2017) en Portugal, Valle en Perú (2014), Kristensen en Dinamarca (2010) y Golin y Cardoso en Brasil (2009). Y por su revisión bibliográfica internacional del tema los de Golin y otros (2014) y Jaakola (2014). Para el establecimiento de temáticas se toman como referencia las aportaciones de Calero (2008), Jurado (2011), Rodríguez (2010), Izquierdo (2014), y teorías clásicas de Rodríguez Pastoriza (2006) Tubau (1982) y Rivera (2003). Para el estudio de los géneros periodísticos, Martínez Albertos (2004a y 2004b), Armentía (2009) y Cantavella (1999); y sobre la jerarquización de textos a López (2004). De los elementos complementarios a Santos (2015), Armentía (2009) y Salaverría (2008). El análisis de contenido en este trabajo otorga un aporte empírico que permite conocer la relación entre las aportaciones de los autores y lo que prudentemente podemos llamar el resultado de la rutina periodística. Golin y sus colegas (Golín, 2014, p. 1) otorgaban gran valor al medio impreso por su carácter hegemónico, documento histórico y mapa para la interpretación de cada periodo histórico. Respaldados por este tipo de afirmaciones, se ha recurrido al estudio de caso de las versiones impresas de los diarios El País, El Mundo y $A B C$, como representativos de España, durante el mes de febrero de 2017. En total se han analizado 565 textos en 84 periódicos.

Los resultados obtenidos son cuantitativos basados en el páginas dedicadas a cada sección y en el número de textos cuándo se analizan temáticas y géneros periodísticos. 
Se han valorado cuatro grupos analizables para cubrir los objetivos establecidos:

1. Elementos relacionados con la tematización y organización en secciones. Se trata de datos cuantitativos del número de secciones, orden que ocupa la sección Cultura, número de páginas que la integran, número de textos, diferenciando los textos 3 o más columnas y número de fotografías.

Objetivo: valorar la importancia otorgada a la sección Cultura respecto al resto y valorar la calidad de los textos desde un punto de vista cualitativo.

2. Temáticas. No se contempla un listado cerrado. Los más significativas son: cine, teatro, danza, ópera, música, toros, arquitectura, exposiciones/museos, política cultural.

Objetivo: conocer los contenidos a los que se les otorga mayor importancia.

3. Géneros periodísticos. Las variables son: breve, noticia, reportaje informativo, reportaje interpretativo, entrevista temática, entrevista de personaje o perfil, crónica, editorial, columna de opinión, artículo de opinión, ensayo, crítica y 'otros'.

Objetivo: conocer la intencionalidad en la difusión de los textos y la variedad de estos.

4. Elementos complementarios. Se han valorado los clásicos como despieces, infografías, fotografías, y otro grupo de elementos innovadores y que son el resultado de la adopción de recursos de las versiones digitales: uso de $\mathrm{QR}$, enlace, mención a páginas web, etc. Sólo en el caso de las fotografías, el resultado se ofrece junto con los datos del primer grupo.

Objetivo: valorar la calidad de la sección en función de los recursos empleados y la posible innovación de la sección.

\section{Resultados: La sección Cultura en la práctica}

\section{Elementos relacionados con la tematización y organización en secciones}

\section{Organización y distribución de las secciones en los periódicos}

Teniendo en cuenta que las dimensiones del diario $A B C$ son inferiores a los otros dos diarios analizados, los datos revelan que durante el mes de febrero la media de páginas destinadas por El País fue de 49, en El Mundo fue de 48 y el $A B C$ de 75. De estos, los destinados a la sección Cultura, y en orden de mayor a menor dedicación fueron, El País, con 5 páginas lo que supuso un $10 \%$ del total; El Mundo, que destinó casi el 7,5\% con una media de casi 4 páginas diarias; seguido de $A B C$, casi un 7\%, con una media de 5 páginas diarias. En cualquier caso se puede valorar que Cultura no recibe nunca más del $10 \%$ de la totalidad de las páginas de los medios impresos.

Figura 2: Sección Cultura respecto al resto del periódico

\begin{tabular}{l|l|l|l}
\hline & $\begin{array}{l}\text { Media del número de } \\
\text { páginas del periódico } \\
\text { durante el mes de febrero }\end{array}$ & $\begin{array}{l}\text { Media del número de } \\
\text { páginas de la sección } \\
\text { Cultura }\end{array}$ & $\begin{array}{l}\text { Porcentaje que representa } \\
\text { la sección Cultura en } \\
\text { relación al resto del diario }\end{array}$ \\
\hline
\end{tabular}




\begin{tabular}{l|l|l|l}
\hline $\boldsymbol{A B C}$ & 75,64 & 5 & $6,61 \%$ \\
\hline EL & 48,18 & 3,61 & $7,49 \%$ \\
MUNDO & & 5 & $10,17 \%$
\end{tabular}

Fuente: Elaboración propia

No cabe duda que este dato resulta interesante, pero obliga a conocer qué posición ocupa en el ranking la sección Cultura con respecto al resto.

Dada la peculiaridad de cada uno de los periódicos, los datos se reflejan por cada uno distinguiendo las secciones más emblemáticas y dejando en un apartado denominado 'Resto' las secciones no diarias y/o con menos de 2 páginas en el día en el que se publica esta sección. Éste es el caso de Motor, Salud, Sanidad, Familia, etc.

Así, El País tuvo por delante de la sección Cultura tres grandes secciones -de las ocho más significativas-, que por este orden fueron: temas nacionales, internacionales y deportes. Dejando por detrás Economía y Opinión, más valoradas por otros diarios. Éste es el caso de El Mundo, que prioriza con hasta cuatro secciones por delante de Cultura. Las secciones más amplias de este diario, y en este orden, fueron: España, Opinión, Internacional y Deportes. Queda muy parejo con los temas de economía y por delante de los temas de sociedad y televisión. En el diario $A B C$, la sección Cultura es prácticamente la última, solo tiene por detrás a Televisión.

Figura 3: Páginas destinadas a cada una de las secciones

\begin{tabular}{|c|c|c|c|c|c|c|}
\hline & \multicolumn{2}{|c|}{ El País } & \multicolumn{2}{|c|}{ El Mundo } & \multicolumn{2}{|c|}{$A B C$} \\
\hline & $\begin{array}{l}\text { Media páginas } \\
\text { diarias }\end{array}$ & $\begin{array}{l}\% \text { del } \\
\text { total }\end{array}$ & $\begin{array}{l}\text { Media páginas } \\
\text { diarias }\end{array}$ & $\begin{array}{l}\% \text { del } \\
\text { total }\end{array}$ & $\begin{array}{l}\text { Media páginas } \\
\text { diarias }\end{array}$ & $\begin{array}{l}\% \text { del } \\
\text { total }\end{array}$ \\
\hline Opinión & 3,86 & 7,86 & 5,54 & 11,50 & 11,43 & 15,11 \\
\hline España & 8,04 & 16,36 & 8,14 & 16,89 & 10,21 & 13,5 \\
\hline Internacional & 7,07 & 14,39 & 4,93 & 10,23 & 6,18 & 8,17 \\
\hline Economía & 4,68 & 9,52 & 3,39 & 7,04 & 5,14 & 6,8 \\
\hline Deportes & 5,86 & 11,93 & 4 & 8,3 & 6,25 & 8,26 \\
\hline Gente (Sociedad) & 1,82 & 3,7 & 2,5 & 5,19 & 5,79 & 7,65 \\
\hline Cultura & 5 & 10,18 & 3,61 & 7,49 & 5 & 6,61 \\
\hline TV y $R$ & 2 & 4,07 & 2,43 & 5,04 & 3 & 3,97 \\
\hline $\begin{array}{l}\text { Publicidad (pág. } \\
\text { completa) (*) }\end{array}$ & 6,79 & 13,82 & 6,79 & 14,09 & 8,18 & 10,81 \\
\hline Resto & 4,02 & 8,17 & 6,85 & 14,23 & 14,46 & 19,12 \\
\hline TOTAL & 49,14 & 100,00 & 48,18 & 100,00 & 75,64 & 100,00 \\
\hline
\end{tabular}

(*) No se ha contemplado la Publicidad como sección, pero se ha conservado el dato cuantitativo

Fuente: Elaboración propia

La valoración que se hace de la sección Cultura oscila del periódico El País, que otorga más peso a los temas culturales, al diario $A B C$, que posiciona la sección Cultura prácticamente en el último puesto del ranking de secciones. Dejando en el centro a El Mundo. 
Los investigadores hablan de la calidad de los contenidos y, en algunas ocasiones, hacen mención a ésta en relación a los elementos que la acompañan: existencia o no de fotografías, número de columnas, posicionamiento en la página, entre los más significativos a nivel de medio impreso, y se amplían y varían en función de otros soportes como pueda ser la televisión o el medio digital. También se asocia la calidad con una adecuada relación entre la cantidad de textos ofrecidos, ya que a mayor número de textos menor tratamiento en profundidad. En esta línea se ha analizado la relación entre el número de fotografías y textos con 3 o más columnas con el número de textos publicados en la sección Cultura; y a su vez la relación entre el número de páginas y el número de textos publicados. El dato que se da es genérico y suficiente para valorar este aspecto y poder extraer valoraciones de interés.

$A B C$ publicó 160 textos durante el mes de febrero. Durante ese tiempo la sección Cultura publicó contenidos en 140 páginas, lo que supone que prácticamente hubo un tema completo por página de media. En el caso de El Mundo fue de 1,5 textos por página; y en El País, 1,8. Desde este enfoque se puede valorar que $A B C$ dedicó más espacio por tema difundido con casi una página, frente a la media página que le otorga de media $E$ País. $A B C$ otorgaría más calidad en tanto que sus textos reciben más espacio.

Al analizar el número de fotografías en relación a los textos publicados, se observa que $A B C$ publicó sus textos con una media de 1,7 fotografías por texto; El Mundo con 1,1, y El País con 0,90, es decir, no llega a una imagen por texto. De modo que $A B C$ otorga más visibilidad a sus textos que el resto de periódicos. Finalmente, al observar el número de textos en relación a los que se han publicado con 3 o más columnas -recordemos que $A B C$ tiene un formato que sólo le permite llegar a las 4 columnas-, $A B C$ publicó, el $70 \%$ de sus textos a tres o más columnas; El Mundo, el 86\%; y El País, 79\%. Prácticamente se igualan, sin tener en cuenta el condicionante del formato, ya que si se tiene en cuenta, los textos de ABC resultan generalmente más extensos que en los otros dos medios.

Figura 4: Relación de páginas con textos publicados, fotografías y columnas

\begin{tabular}{l|c|c|c}
\hline \multicolumn{1}{c|}{ Sección Cultura } & ABC & El Mundo & El País \\
\hline Total Páginas & 140 & 101 & 140 \\
\hline Total Textos publicados & 160 & 157 & 248 \\
\hline Total Fotografías & 270 & 168 & 217 \\
\hline $\begin{array}{l}\text { Total textos con 3 o más } \\
\text { columnas }\end{array}$ & 112 & 135 & 195 \\
& Fuente: Elaboración propia
\end{tabular}

\section{Temáticas de la sección Cultura}

En los tres diarios el cine ha sido uno de los temas más repetidos, aunque no en todos los casos el primero del ranking. En $A B C$ sí ha sido el que más veces se ha repetido, representado un $31 \%$. Le siguen los relativos a Arte (16\%) y Música (12\%). En el caso de El Mundo, la literatura ocupa este primer puesto (25\%), le siguen el cine (18\%) y la música (11\%). El País, retoma el cine en primera posición con un $27 \%$ pero seguido de cerca por los temas literarios (22\%) y de arte (14\%). De esta manera los grandes temas 
que se tratan en la sección Cultura en los tres periódicos son Cine, Literatura, Música y Arte, que en el caso de $A B C$ supone el $70 \%$ de la totalidad temática; en El Mundo el 64\%; y El País es el $75 \%$.

Figura 5: Comparativa temas sección Cultura $A B C$, El Mundo y El País

\begin{tabular}{lllllll}
\hline & $\boldsymbol{A B C}$ & & El Mundo & \multicolumn{3}{c}{ El País } \\
\hline Cine & Textos & $\%$ & Textos & $\%$ & Textos & $\%$ \\
\hline Teatro & 50 & 31,25 & 28 & 17,83 & 66 & 26,61 \\
\hline Danza & 5 & 3,13 & 10 & 6,37 & 18 & 7,26 \\
\hline Ópera & 2 & 1,25 & 4 & 2,55 & 1 & 0,40 \\
\hline Música & 1 & 0,63 & 3 & 1,91 & 6 & 2,42 \\
\hline Literatura & 17 & 11,88 & 17 & 10,83 & 31 & 12,50 \\
\hline Arte & 25 & 10,63 & 40 & 25,48 & 55 & 22,18 \\
\hline Exposiciones & 1 & 0,63 & 7 & 16,19 & 34 & 13,71 \\
\hline Toros & 10 & 6,25 & 4 & 2,55 & 0 & 0,00 \\
\hline Otros & 30 & 18,72 & 28 & 17,83 & 29 & 11,69 \\
\hline TOTAL & 160 & 100,00 & 157 & 100,00 & 248 & 100,00 \\
\hline & & Fuente: Elaboración propia & &
\end{tabular}

Géneros periodísticos de la sección Cultura

La sección Cultura presenta gran variedad de géneros. En el caso de $A B C$ la noticia fue el más difundido con 36 textos, seguido de los 23 reportajes informativos y de las 18 crónicas. En general se trabajaron 11 géneros diferentes. Curiosamente, y al contrario de lo que se podría esperar de la sección cultural, sólo se publicaron 2 críticas. Valorando la suma de los géneros en función de la intencionalidad de los contenidos difundidos en función del género con el que se publica, los géneros más difundidos han sido los interpretativos (53\%), seguidos de los informativos (33\%) y finalmente los de opinión (14\%). 
Figura 6: $A B C$ : géneros periodísticos sección Cultura

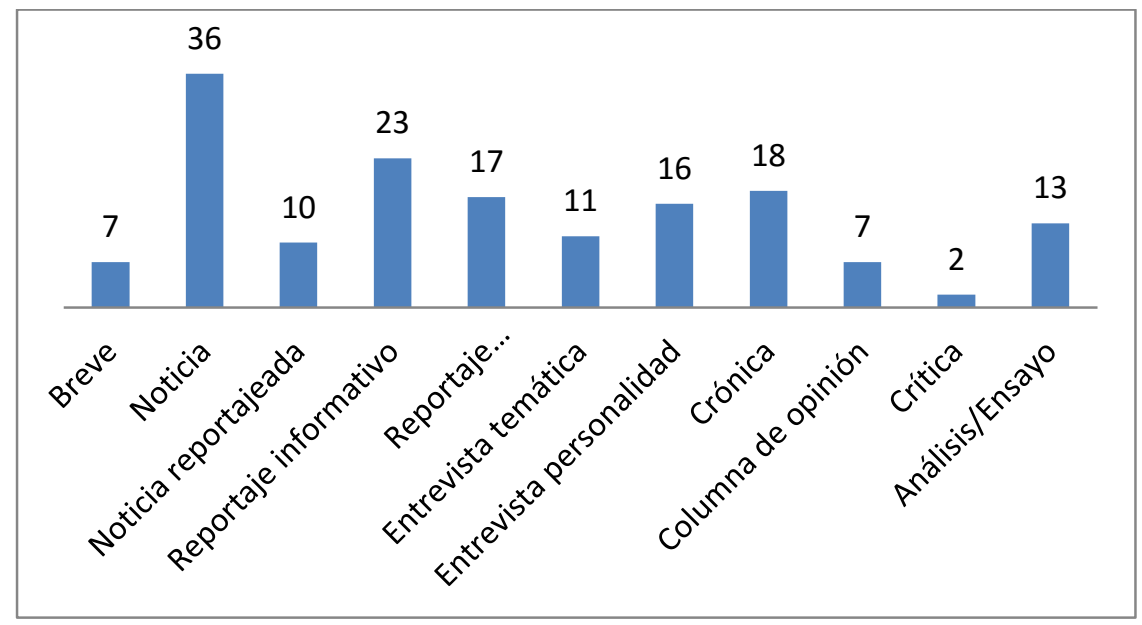

Fuente: Elaboración propia

El Mundo publicó prácticamente los mismos géneros, un total de 10 diferentes entre los que la columna de opinión fue la más repetida, en 27 ocasiones, seguido de las 25 noticias y de los 20 reportajes informativos. Se trabajó menos el reportaje en profundidad o interpretativo. En la curva de la tendencia de intencionalidad se observa la importancia dada por igual a los géneros informativos y los de opinión. Agrupándolos por intencionalidad, los interpretativos siguen siendo los más numerosos (41\%), seguido de los de opinión (37\%) y por último los informativos (22\%).

Figura 7: El Mundo: géneros periodísticos sección Cultura

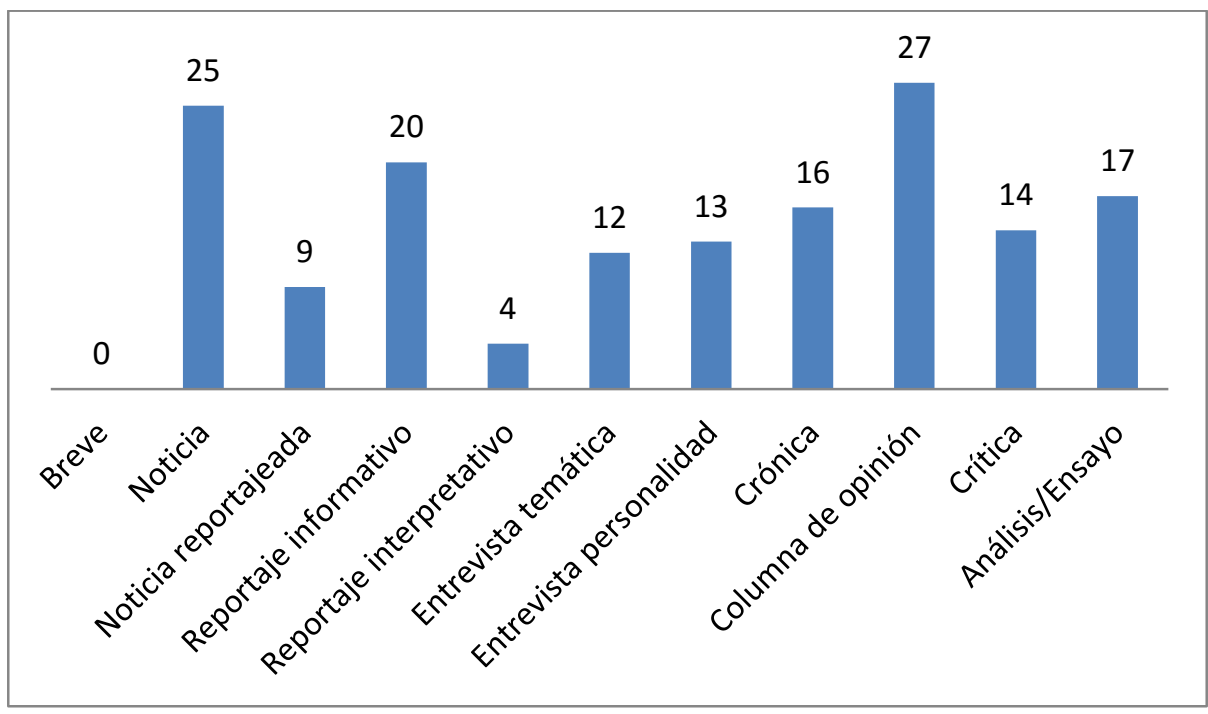

Fuente: Elaboración propia

En El País también se publicaron 10 géneros diferentes, de los que el más numeroso fue la noticia con 51 textos, seguido del reportaje informativo con 47 y de la crítica con 30. Menos significativos fueron la 
entrevista o el análisis o ensayo ${ }^{3}$. Por intencionalidad de los géneros, los interpretativos son los más numerosos (42\%), seguido a partes iguales de los de opinión y los informativos, con $29 \%$ cada uno.

Figura 8: El País: géneros periodísticos sección Cultura

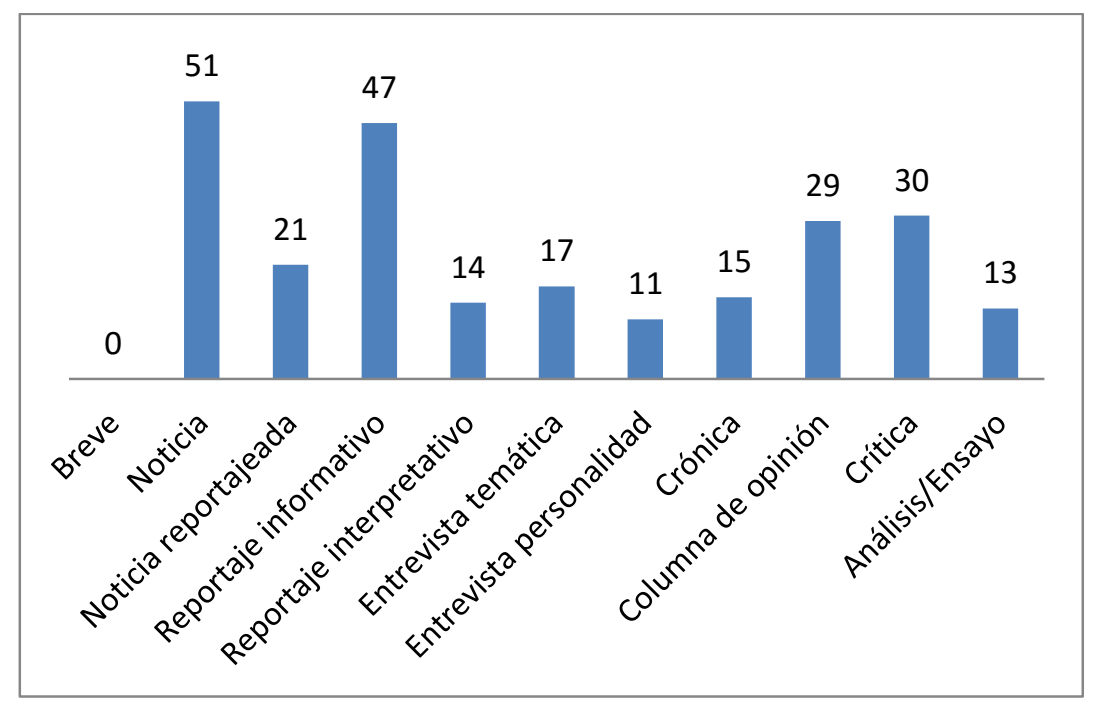

Fuente: Elaboración propia

Se puede valorar finalmente en relación a este epígrafe que la noticia y el reportaje informativo son los más difundidos; seguido de la crónica en $A B C$, la columna de opinión, en El Mundo; y la crítica en El País. El elemento diferenciador de los tres medios fue la elección del género de opinión para la difusión de textos: más elaborado, periodístico y con implicación más frecuente de enviados especiales en el caso de $A B C$; de contenido genérico, más divulgativo y sin presencia obligada de periodistas, en El Mundo; y de expertos, generalmente periodistas, en El País. A pesar de estos datos, los géneros con intencionalidad interpretativa han presentado casi el 45\%, seguido casi por igual de los informativos (28\%) y los de opinión (27\%).

Figura 9: Géneros periodísticos empleados en los periódicos analizados

\begin{tabular}{lrrrrrrr}
\hline & \multicolumn{2}{c}{ ABC } & \multicolumn{2}{c}{ El Mundo } & \multicolumn{2}{c}{ El País } \\
\hline Breve & $N^{0}$ & $\%$ & No & $\%$ & $N^{\circ}$ & $\%$ \\
\hline Noticia & 7 & 4,38 & 0 & 0,00 & 0 & 0,00 \\
\hline Noticia reportajeada & 36 & 22,50 & 25 & 15,92 & 51 & 20,56 \\
\hline Reportaje informativo & 10 & 6,25 & 9 & 5,73 & 21 & 8,47 \\
\hline Reportaje interpretativo & 23 & 14,38 & 20 & 12,74 & 47 & 18,95 \\
\hline Entrevista temática & 17 & 10,63 & 4 & 2,55 & 14 & 5,65 \\
\hline Entrevista personalidad & 11 & 6,88 & 12 & 7,64 & 17 & 6,85 \\
\hline
\end{tabular}

3 Tras el análisis de contenido se ha contemplado el análisis y el ensayo como un mismo género por la similitud en su estructura y contenido en esta sección concreta. 


\begin{tabular}{lrrrrrr} 
Crónica & 18 & 11,22 & 16 & 10,19 & 15 & 6,05 \\
\hline Columna de opinión & 7 & 4,38 & 27 & 17,20 & 29 & 11,69 \\
\hline Crítica & 2 & 1,25 & 14 & 8,92 & 30 & 12,10 \\
\hline Análisis/Ensayo & 13 & 8,13 & 17 & 10,83 & 13 & 5,24 \\
\hline TOTAL & 160 & 100,00 & 157 & 100,00 & 248 & 100,00
\end{tabular}

Fuente: Elaboración propia

\section{Elementos complementarios de la sección Cultura}

Los elementos complementarios que se han encontrado son escasos y muestran poca innovación en el uso de recursos. Los despieces son el elemento más empleado en los tres diarios, si bien $A B C$ suele acompañar prácticamente todos los días un texto interpretativo de otro informativo que lo complementa, ya que se publicaron 28 despieces. Los otros dos diarios recurren a este género con menos frecuencia, 12 en el caso de El Mundo y 17 en El País. Por lo que tiene que ver con el uso de infografías, los tres periódicos las emplean en muy pocas ocasiones, siendo una media de 3 diarias durante el mes de análisis. El uso de otros recursos adaptados de las versiones digitales es casi anecdótico en los tres diarios. Así puede verse en la mención en $A B C$ a su página web, que incluye la dirección de la versión digital de la versión impresa; y el uso de QR para la información de la cartelera de cine en El Mundo.

Sólo hay hipertextualidad en $A B C$, a una media de un texto diario con el uso de despieces y, en tanto solo 9 ocasiones durante todo el mes de análisis, con invitación a consultar contenidos en otras páginas web. Hay multimedialidad en tanto que casi todos los textos van acompañados de fotografía; no hay interactividad ni se fomenta; y no hay simultaneidad por las limitaciones del formato.

Figura 10: Elementos complementarios

\begin{tabular}{lccc}
\hline & $\boldsymbol{A B C}$ & $\begin{array}{c}\boldsymbol{E} \boldsymbol{} \\
\text { Mundo }\end{array}$ & $\boldsymbol{E l}$ País \\
\hline Despieces & 28 & 12 & 17 \\
\hline Infografía & 4 & 3 & 2 \\
\hline Enlaces a páginas web & 43 & 1 & 1 \\
\hline QR & 0 & 16 & 0 \\
\hline Hashtag & 2 & 0 & 0 \\
\hline Invitación a consultar & & & \\
contenidos en otra página & 9 & 0 & 0 \\
web & & &
\end{tabular}

Fuente: Elaboración propia 


\section{Discusión}

Son numerosas y dispersas las propuestas sobre qué debe contener la sección Cultura. A partir de los autores citados se han detallado los requisitos de esta sección en cuatro bloques de los que se ha observado su cumplimiento con el análisis de contenido:

Bloque 1: Organización y distribución en secciones y jerarquía y la calidad de los textos

- El orden en el que se ofrecen las secciones es intencionado y determina el perfil del lector. La distribución clásica es: política internacional, nacional, local economía, cultura, sucesos y deportes, y se identifica con un lector conservador de edad avanzada. La sección Cultura debe contextualizar los fenómenos culturales, reflejar las problemáticas globales de una época y hacernos comprender lo ocurrido, entre otros. Como se ha visto en los resultados, esta sección apenas llega al 10\% del espacio total del medio y aparece de la mitad en adelante, excepto en el caso de $A B C$ que aparece en penúltimo lugar. Coincide con la importancia relativa que le dan los autores en el caso de los medios más progresistas, pero no coincide en el caso del más conservador de los analizados.

- La calidad viene determinada por la extensión y la existencia de elementos complementarios como fotografías, despieces e infografías. En los resultados del análisis se aprecia que casi el $80 \%$ de los textos se publican a tres o más columnas, es decir, son textos de grandes dimensiones, y que, de media, todos tienen poco más de una fotografía. Se puede decir que en la práctica los medios tratan de lograr la calidad de los textos coincidiendo con los requisitos establecidos por los investigadores.

Bloque 2: Temáticas

- Los investigadores enumeran un listado: literatura, arte, cine, teatro, danza, nuevas tecnologías y arquitectura. Mencionan de forma excepcional: moda, gastronomía, científico y exposiciones. En el análisis se comprueba que cine, literatura, música y arte representan el $70 \%$ del total. Todos los temas propuestos por los autores se recogen en el análisis excepto los científicos; presencia de textos de temática taurina, que los autores no mencionan; y los relativos a gastronomía y moda, que se integran en la sección de Sociedad.

\section{Bloque 3: Géneros periodísticos}

- Pueden englobarse en dos grupos. Por un lado los que apuntan a una tendencia genérica de lo que debería ser el Periodismo Cultural. Por otro lado, las propuestas específicas respaldadas por análisis de casos o de contenido. Estas tendencias coinciden con los resultados del análisis. El estudio de los géneros periodísticos determina si el objetivo del medio es informar, formar o dar opinión. Según los autores, el medio lleva a cabo su función de contextualizar, hacer comprender lo ocurrido, espíritu crítico, reflejo de las problemáticas sociales, transparencia para asegurar la neutralidad frente a la relación 'industria-cultura' y frente a los intereses del medio, etc. Con los datos de unos y otros en la mano, se puede afirmar que la tendencia en el uso de los géneros interpretativos casi en el $50 \%$ confirma que en este porcentaje los medios persiguen estos objetivos. No obstante, hay otro $50 \%$ que 
se diluye en otros objetivos. Los autores criticaban que con frecuencia se caía en la mera opinión en lugar de explicar. Si bien la balanza cae a este lado en el caso de El Mundo y de El País, no es el caso de $A B C$, donde los géneros de opinión representan sólo el $14 \%$.

La predicción de Cantavella (1999, p. 72-73) se cumple en los puntos en los que la noticia se diluiría en breves o 'noticias reportajeada', el mayor uso de los géneros interpretativos y la pérdida de nitidez de la opinión y la información; pero se incumple en el valor añadido que da al uso de la entrevista perfil, de los despieces y la columna menos subjetiva.

\section{Bloque 4: Los elementos complementarios}

- $\quad$ Ayudan a comprender la información y los autores preveían la pujanza de la fotografía y la infografía en paralelo al desarrollo de los medios digitales; aunque se tenía poca esperanza en el uso de los recursos propios del nuevo soporte relativo a las posibilidades de hipertextualidad, multimedialidad, interactividad y simultaneidad.

Como se ha podido ver, en algunas propuestas acertaron y en otras no. Sí se han empleado más fotografías lo que ha hecho más visuales las páginas, pero no ha ocurrido así con el resto de elementos: apenas se emplearon infografías, que podría pensarse que es el recurso más accesible; y menos los propios del medio digital, como pueda ser la mención a enlaces, uso de QR, hashtag, etc. En este sentido, las propuestas de los autores que apostaron por una renovación de la sección Cultura como vía para asegurar su supervivencia apenas han prosperado.

\section{Conclusión}

La sección Cultura es una clásica dentro del temario ofrecido por los medios. Son numerosos los estudios que destacan su valor dentro del periodismo especializado y los requisitos que debe cumplir. A lo largo del tiempo su contexto ha cambiado y los autores han ido variando las propuestas para la modernización y supervivencia que caminan de la mano de las definiciones tradicionales. De puertas hacia afuera la sección Cultura cumple con los requisitos que los investigadores les otorgan, pero, ¿estas características se dan realmente en sus contenidos? El punto de partida de este artículo se ha centrado en conocer la relación y el posible desequilibrio entre las aportaciones teóricas y la práctica.

Para este trabajo se ha llevado a cabo una profunda revisión bibliográfica, fijando los ojos en autores clásicos y actuales, como han sido los estudios de Cruz y Rosero (2012), Baptista (2017), Valle (2014), Kristensen (2010), Golin y Cardoso (2009), Golin y otros (2014) y Jaakola (2014).

Los autores coinciden que es una de las secciones más rica en variedad de contenidos y géneros periodísticos; que sin ser una de las principales del medio, sí es emblemática y considerada en cuanto que abiertamente describe y difunde su ideología partiendo del concepto más amplio de cultura, más allá de lo periodístico, pasando por el interés empresarial, sociológico o antropológico. Este espacio estimula la creatividad temática de los redactores, aunque no la explota por completo. Cine, música, arte y literatura copan contenidos de noticias, reportajes informativos y crónicas, pero no agotan sus posibilidades, ni en lo concerniente a la riqueza en la variedad de temas ni de géneros, cayendo con facilidad en repetición de 
escenarios, personajes y temas, y redundando en los defectos de las rutinas de la organización empresarial comunes al resto de la agenda del medio.

Las posibilidades de hipertextualidad, multimedialidad, interactividad y simultaneidad y la hibridación de géneros y formatos propias del medio digital, son propuestas de un modelo que parece quedar lejano y ajeno a los contenidos culturales en las secciones genéricas de los medios impresos, frente a las propuestas más innovadoras que nacen de las revistas, web o blogs especializados en cultura entendida en el campo de las artes y las letras. No ocurre lo mismo con la tendencia al consumismo y modelo de entretenimiento de la sección cultura con la inserción de áreas periféricas a las tradicionales (Santos, 2015: 309) y un enfoque más comercial (Kristensen, 2010, p. 69).

Pero tampoco se atisban iniciativas que exploren nuevas vías. Como ha podido comprobarse en este estudio, el soporte papel mantiene la cabeza alta en la difusión de contenidos culturales propios de esta especialización periodística. Las referencias teóricas y la práctica coinciden en la mayoría de las ocasiones. Esto es, las propuestas teóricas dadas por los autores y los textos publicados en las páginas de los periódicos, coinciden con los resultados de este estudio, sin embargo, no ocurre lo mismo cuando se trata de previsiones de cara a la modernización de la sección. Probablemente sea así porque la sección Cultura apenas ha cambiado desde los primeros estudios teóricos hasta nuestros días. Las temáticas coinciden a grandes rasgos, se perpetúan dos tendencias: una cultura de élite ${ }^{4}$-acomodada en esta sección-, y otra popular que abandona la sección Cultura para ubicarse en la de Sociedad. Se reclama calidad y crítica (Soler, 2012, p. 183), "no confinarse en el pasado e ignorar el impacto de todo lo digital" (Santos y Torres, 2017, p. 43). En este punto los investigadores no se ponen de acuerdo: a pesar de la claridad con la que algunos aventuran que sin innovación la sección está sentenciada a desaparecer, otros defienden que su peso ideológico le otorga inmunidad.

El presente de la sección Cultura en los medios impresos trata de mantener el status cultural del periódico -entendido como pedagógico o educativo-, independientemente de su contenido, como una obligatoriedad de reflejar la cultura de la sociedad en la que está inserta -entendida como tradición, distintivo elitista de una sociedad determinada- y justificándolo en términos de valores del medio aunque supongan pérdidas 0 menor ingreso, casi más por una cuestión ética y moral que empresarial. Se intuye finalmente que el futuro de la sección pasa por identificar el sentido que el medio da a la sección Cultura: si como empresa se libera de las ataduras de un contenido que no le interesa y logra justificar su desaparición achacándolo a terceros; o si se libera de los complejos y apuesta por cumplir con una función formadora e identificadora de la sociedad, que no desecha necesariamente lo anterior, sino que lo nuevo con lo viejo le sirve para explorar y trasmitir nuevas dimensiones del fenómeno cultural (Valle, 2014, p. 131). Mientras tanto, se mueve entre dos aguas.

Por este motivo, estudiar las versiones impresas suponía un punto de partida indiscutible, porque son los medios impresos los que iniciaron la organización en secciones de lo que se difunde al lector, y los que todavía dilatan el desenlace a la especialización frente a la generalización de los contenidos. Mientras en el resto de soportes, digital, televisión, radio, el público selecciona contenidos y discrimina otros, en los medios impresos, se sigue ofreciendo un poco de todo asumiendo que así lo quieren sus lectores.

\footnotetext{
${ }^{4}$ Concepto de cultura de élite y cultura popular tomada de Rodríguez Pastoriza (2006)
} 


\section{Bibliografía}

Aguilar, J. (2009). ¿El fin del periodismo cultural? www.Letraslibres.com. Consultado en: https://goo.gl/oB5Ym5

Armañanzas, E. y Díaz Noci, J. (1996). Periodismo y argumentación: géneros de opinión. Bilbao: Universidad del País Vasco.

Armentia Vizuete, J.I. y Caminos Marcet, J.M. (2009). Redacción informativa en prensa. Barcelona: Ariel Comunicación.

Arráez Betancort, R. M., Jensen Casado, E. y Pascual Pérez, C. (2014). Periodismo cultural en la postmodernidad. Historia y Comunicación Social, 19, 49-61.

Baptista, C. (Coor.) (2017). A Cultura na Primeira Página: Uma Década de Jornalismo Cultural na Imprensa em Portugal. Lisboa: Escritório Editora.

Barei, (1999). Periodismo Cultural: crítica y escritura. Revista Latina de Comunicación Social, 23. Consultado en: http://www.revistalatinacs.org/a1999bno/15silvia.html

Bello, J., Gondella, I y Quiaro, E. (1994). Periodismo cultural diario entre la modernidad y la posmodernidad en busca de la definición perdida. Caracas, Venezuela: Colección Canícula.

Bourdieu, Pierre. (1997). The field of cultural production. Londres: Polity Press.

Cantavella, J. (1999). Textos dinámicos y atractivos para un periodismo cambiante. Aproximación a las tendencias de futuro en los géneros periodísticos. Estudios sobre el Mensaje Periodístico, 5, 6375.

Camacho, I. (2010). La especialización en el periodismo. Formar para informar. Sevilla/Zamora: Comunicación Social.

Casals Carro, M. (2005). Periodismo y sentido de la realidad. Teoría y análisis de la narrativa periodística. Madrid: Fragua.

Cavallín, C. (2009). Del twitter como plaza o cómo se configuran los Nuevos espacios para el periodismo cultural. Disertaciones, 2 (2), 89-103.

Colle, R. (1998). Estilos o tipos de infógrafos. Revista Latina de Comunicación Social, 12.

Cortés Montalvo, J.A. y García Pérez, J.A. (2012). Relaciones entre periodismo y literatura: fusión sin confusión. Pangea, 3, 39-50.

Cruz. P y Rosero, S. (2012). El periodismo cultural en la prensa de Ecuador. En Revista ComHumanitas, volumen 3 (3), 183-195.

De Pablos, J.M. (1993). Infografía o infoperiodismo, el nuevo género periodístico: ¿cómo y cuándo? Comunicación y Sociedad, 18-19: 257-277.

Dillon, A. (2011). La construcción periodística del campo cultural. Buenos Aires: Educa.

Delponti y Pestano, J.M. (2012). El papel del periodismo cultural en la construcción simbólica de un imaginario social globalizado. En Actas del IV Congreso Internacional Latina de Comunicación, Universidad de la Laguna. en http://www.revistalatinacs.org/12SLCS/2012 actas/192 Delponti.pdf

Díaz, L.; Murillo, M.; \& Oromi, L. (2005). Periodismo cultural y farándula en la prensa chilena actual: los casos de los diarios Las Últimas Noticias y La Cuarta. Tesis de pregrado publicada. Universidad de Playa Ancha, Chile.

Domínguez Quintas, S. y Doval Avendaño, M. (2013). La necesaria transformación de los géneros del papel al ciberperiodismo. Historia y Comunicación Social, 18, 187-197. 
Edo, C. (1999). Las revistas e Internet como soportes del periodismo especializado y la divulgación. Estudios sobre el Mensaje Periodístico. 5, 77-96.

Esteve Ramírez F. (2012). Fundamentos de la especialización periodística. En Camacho, Idoia. La especialización en el periodismo, Formarse para informar. Sevilla/Zamora: Comunicación Social.

Esteve Ramírez F. y Fernández del Moral, J. (1999). Áreas de especialización periodística. Madrid. Fragua.

Fernández Parrat, S. (2001). El debate en torno a los géneros periodísticos en la prensa: nuevas propuestas de clasificación. ZER Revista de Estudios de Comunicación, 6, 293-310.

Fontcuberta; M. (1998). La noticia. Pistas para percibir el mundo. Barcelona: Paidós Ibérica.

García, M; López, M y Ruiz, M. (2011). Medios de comunicación y cultura; ¿cultura a medias? Barcelona: Los libros de la frontera.

Golin, C. y Cardoso, E. (2009). Cultural journalism in Brazil: Academic research, visibility, mediation and news values. Journalism, 10(1), 69-89.

Golin, C., Cardoso, E., Sirena, M. y Linhares, B. (2014). Jornalismo cultural: Pesquisa internacional sobre artigos registrados em bases de dados. En Lumina, 8 (2).

Gómez-Escalonilla, G. (2014). La puesta en marcha del Máster Oficial de Periodismo Cultural y Nuevas Tendencias en la Universidad Rey Juan Carlos. En Esteve, F. y Nieto, J.C. Nuevos retos del periodismo especializado (pp. 23-34). Madrid: Schedas.

Gomis, L. (1991). Teoría del periodismo. Cómo se forma el presente. Barcelona: Paidós.

Grijelmo, A. (2006). El estilo del periodista. Madrid: Taurus.

Hanitzsch, T. (2006) Mapping Journalism Culture: A Theoretical Taxonomy and Case Studies from Indonesia. En Asian Journal of Communication, 16(2), 169186. DOI: $\underline{10.1080 / 01292980600638835}$

Herrero, C. (1999). La cultura como área de especialización periodística: la crítica y su dimensión hermenéutica. En VV.AA., Estudios de Periodística VII. Periodismo de promoción cultural. Bilbao: Universidad del País Vasco.

Ivars Nicolás, B. (2016). Las infografías en línea de elpais.com para los JjOO Río 2016. En Jurado Martín, M. y otros (Coord.) Mobile First. Comunicación Multipantalla. Murcia: Diego Marín.

Izquierdo Expósito, V. (2014). Análisis de la información artística en los medios escritos generalistas españoles (El País, El Mundo y ABC). Estudios sobre el Mensaje Periodístico, 20 (2), 1121-1130.

Jaakkola, M. (2014). Witnesses of a cultural crisis: Representations of media-related metaprocesses as professional metacriticism of arts and cultural journalism. International Journal of Cultural Studies, 18(5), 537-554 doi: 10.1177/1367877913519308

Jurado Martín, M. (2011). La literatura en la prensa diaria. Una reflexión sobre la sección Cultura en los periódicos. En Blanco, I. y Fernández Martínez: (Coord.) Entre la ficción y la realidad. Perspectivas sobre periodismo y literatura. Madrid: Fragua.

Jurado Martín, M. y Peña Acuña, B. (2018). Periodismo cultural en el siglo XXI. Contenidos docentes innovadores. Madrid: Universitas.

Llano, R. (2008). La especialización periodística. Madrid: Tecnos.

López, M. (2007). Cómo se fabrican las noticias. Fuentes, selección y planificación. Barcelona: Paidós.

López, M. (2004). Nuevas competencias para la prensa del siglo XXI. Barcelona: Paidós.

López, X. (2004). Información Cultural. En Fernández del Moral, J. Periodismo Especializado. Barcelona. Arial. 
Martínez Albertos, J. (2004a). Aproximación a la teoría de los géneros periodísticos. En Cantavella, Juan y Serrano Oceja, José (coords.) Redacción para periodistas: informar e interpretar (pp. 51-75). Barcelona: Ariel.

Martínez Albertos, J. (2004b). Curso general de redacción periodística: lenguaje, estilos y géneros periodísticos en prensa, radio, TV y cine. Madrid: Tecnos.

Martínez Albertos, J. (1989). El lenguaje periodístico. Estudios sobre el mensaje y la producción de textos. Madrid: Paraninfo.

Martínez Fresneda, H. (2011). La comunicación, base de toda creación periodística y literaria. En Blanco, I. y Fernández Martínez: (Coord.) Entre la ficción y la realidad. Perspectivas sobre periodismo y literatura. Madrid: Fragua.

Mejía Chiang, C. (2012). Géneros y estilos de redacción en la prensa. Desarrollo y variantes taxonómicas.

Correspondencias \& Análisis. Consultado en:

https://es.scribd.com/document/160530518/Generos-y-estilos-de-redaccion-en-la-prensa

Moreno: (1998). Las formas de expresión en el periodismo cultural. Revista Latina de Comunicación, 11.

Muñoz-Torres, J.R. (2002). Por qué interesan las noticias. Barcelona: Herder.

Nete Nrgaard, K. (2012) Lifestyle journalism: Blurring boundaries. En: UnniIn: Journalism Practice, 6(1), 26-41. https://doi.org/10.1080/17512786.2011.622898

Nete Nrgaard, K. (2010). The historial transformation of cultural journalism. Northern Lights: Film \& Media Studies Yearbook, 8(1), 69-92. doi: 10.1386/nl.8.69_1

Núñez Ladevéze, L. (2007). Los géneros periodísticos y la opinión. En Cantavella, Juan y Serrano Oceja, José (Coord.) Redacción para periodistas: opinar y argumentar (pp. 15-54). Madrid: Universitas.

Núñez Ladevéze, L. (2004). El periodismo desde un enfoque interdisciplinar. En Cantavella, Juan y Serrano, J.F. (Coord.) Redacción para periodistas: informar e interpretar (pp. 17-50). Madrid: Ariel Comunicación.

Núñez Ladevéze, L. (1995). Introducción al periodismo escrito. Barcelona: Ariel Comunicación.

Orihuela, J.L. (2012). 80 Claves sobre el futuro del periodismo. Madrid: Anaya Multimedia.

Rivera, J. (2003). El periodismo cultural. Buenos Aires, Argentina: Paidós

Rebollo Sánchez, A. (2000). Literatura y periodismo hoy. Madrid: Editorial Fragua.

Rodrigo Alsina, M. (1996). La construcción de la noticia. Barcelona: Paidós.

Rodríguez González, J.L. (2011). La cultura del periodismo cultural. En www.mesadetrabajo.com. Consultado en: https://goo.gl/2xBGqP

Rodríguez Martínez, R. (2012). Explicar y difundir la cultura. En Camacho, Idoia. La especialización en el periodismo, Formarse para informar. Sevilla/Zamora: Comunicación Social.

Rodríguez Pastoriza, F. (2006). Periodismo cultural. Madrid: Síntesis.

Rodríguez Pastoriza, F. (2003). Cultura y televisión. Una relación de conflicto. Barcelona: Gedisa.

Ruano López, S. (2009). Contenidos culturales en las televisiones generalistas. Madrid: Fragua.

Sabés Turmo, F. y Carniel Burgs, R. (2013). Tratamiento de los géneros periodísticos en la información de la prensa euromediterránea. Historia y Comunicación Social, 18, 15-32. Consultado en: http://revistas.ucm.es/index.php/HICS/article/view/43945/41552

Sánchez Calero, L. (2008). Una revisión de los géneros periodísticos en la información especializada. Doxa Comunicación, 6. Consultado en https://goo.gl/gvcYr8

Santamaría Suárez, L. (1994). Estado actual de la investigación sobre la teoría de los géneros periodísticos. Estudios sobre el mensaje periodístico, 1, 37-56. 
Santos Silva, D. (2015). Cultural Journalism in a Digital Environment New Models, Practices and Possibilities. Tesis doctoral. Edita: Universidad Nova de Lisboa.

Santos, D. y Torres, M. "Definições, tendências e marcas discursivas do Jornalismo Cultural". En Baptista, C. (Coor.) (2017). A Cultura na Primeira Página: Uma Década de Jornalismo Cultural na Imprensa em Portugal. Lisboa: Escritório Editora.

Torres, M. y Santos, D. (2014). Trends and transformations within cultural journalism: a case study of newsmagazine Visão. Observatorio, 8 (4), 171-185.

Tubau, I. (1982). Teoría y práctica del periodismo cultural. Barcelona: A.T.E.

Valle Vera, M.G. (2014). El periodismo cultural en los diarios limeños de hoy. Una nueva propuesta conceptual. Análisis de los casos de El Comercio, La República y El Peruano. Tesis de licenciatura, 2014. Lima, Perú: Universidad peruana de ciencias aplicadas.

Villa, M.J. (2000). Una aproximación teórica al periodismo cultural. Revista Latina de Comunicación Social, 35.

Williams, Raymond (2017). La cultura de la clase obrera. Revista Rey Desnudo: Revista de Libros, 5 (10).

Zallo, R. (2011). Estructura de la comunicación y de la cultura. Políticas para la era digital. Barcelona: Gedisa.

Zambrano Morales, M.G. y Villalobos Finol, O. (2010): Presencial del periodismo cultural y de espectáculo en la prensa zuliana. Anagramas, Universidad de Medellín, 9(17), 67-82. 